\title{
Levels and Predictors of Food Insecurity among HIV Positive Adult Patients Taking Highly Active Anti-Retroviral Therapy at Arba Minch General Hospital, Southern Ethiopia, 2016
}

Zelalem Nigatu Belijo and Mende Mensa*

Department of Pharmacy, Arba Minch University, Ethiopia

*Corresponding author: Mende Mensa, Clinical Pharmacist, Lecturer and Researcher, Department of Pharmacy, Arba Minch University, Ethiopia, Tel: +2510937170976; Fax: +2510468811147; E-mail: mendemensa@gmail.com

Red date: September 01, 2017; Acc date: September 25, 2017; Pub date: September 28, 2017

Copyright: (C) 2017 Belijo ZN, et al. This is an open-access article distributed under the terms of the Creative Commons Attribution License, which permits unrestricted use, distribution, and reproduction in any medium, provided the original author and source are credited.

\section{Abstract}

Background: Food insecurity and HIVIAIDS are interrelated in with each other. Food insecurity is one of a key contributor of the HIVIAIDS related morbidity and mortality in the world. Therefore this study was conducted to determine the Prevalence and predictors of food insecurity in order to give current evidence to design intervention measures for improvement of food security.

Objective: To determine Prevalence and predictors of food insecurity among HIV positive adults attending ART clinic at Arba Minch hospital, Southern Ethiopia March, 2016.

Methods: Hospital based cross sectional study design was carried out from February 15, 2016 to March 30, 2016 at Arba Minch General Hospital. Data was analyzed by using statistical package for social sciences/SPSS version 20. Frequency and cross tabulation was conducted to clean data and describe the study variable in relation to outcome. Binary logistic regression analysis was computed to assess the crude association between dependent and independent variables. Variables which showed association in binary logistic regression analysis and have P-value less than 0.25 were entered in to Multivariable logistic regression model, to identify significant factors associated with outcome variables by controlling confounding factors. Finally the level of significance was set at $\mathrm{P}$-value less than 0.05

Result: There was 394 study participants involved in this study. Majority of them 260(66\%) were females, $127(39.3 \%)$ of study participants were in age range of $30-39$ years with mean age of $26.65 \pm 10.48$ years, ranging from $18-60$ years. Forty six (11.7\%) participants reported that they have experienced HAART related side effect in the past six months. Ninety two $(23.4 \%)$ consumed less than three meals per day and $26(6.6 \%)$ of the respondents consumed below 3 food items. The Prevalence of food insecurity was 77(19.5\%). Being female [AOR=2.93(1.16, $7.40)$ ]; Rural residence [AOR=3.59(1.65, 7.836)]; monthly income less than 1000 Eth birr $[A O R=6.16(2.33,16.32)]$; Having WHO clinical three \& four disease $[A O R=4.78(1.95,11.69)]$; Developing OIS [AOR=8.03(3.84, 16.78)] and Poor adherence to treatment $[A O R=8.96(3.48,23.05)]$ were independent predictors of food insecurity.

Conclusion and Recommendation: In conclusion about one fifth of participants were food insecure. Factors independently predicting food insecurity were being female, Low monthly income, rural residence, having WHO stage III and IV disease, developing opportunistic infection and none adherence to ART treatment. Emphasis should be given by responsible bodies to address these predicting variables to alleviate food insecurity problem.

Keywords: Food insecurity; HIV/AIDS; Arba minch; General hospital; Ethiopia

Abbreviations: AIDS: Acquired Immunodeficiency Syndrome; BMI: Body Mass Index; BWL: Body weight loss; EDHS: Ethiopia Demographic Health Survey; EPHA: Ethiopian Public Health Association; ETB: Ethiopian Birr; HAART: Highly Active Anti Retro Viral Therapy; HIV: Human Immune Deficiency Virus; MOH: Ministry of Health; OIs: Opportunistic Infections; PLWHIVA: People Living with HIV/AIDS; SPSS: Statistical Package for Social Science; WHO: World Health Organization

\section{Introduction}

Food insecurity is a temporary or complete lack and/or decline in access to productive resources, deterioration of the household assets position over time, declining resource productivity because of environmental degradation and lack of alternative technologies. It is simply the lack of food security that, at the extreme, is experienced as hunger [1].

Human Immunodeficiency Virus (HIV) and malnutrition can independently cause progressive damage to the host immunity. HIV increases vulnerability to different infections like, fever, diarrhea, loss of appetite, nutrient malabsorption, and weight loss and associated morbidity and mortality [1-3]. 
Citation: Belijo ZN, Mensa M (2017) Levels and Predictors of Food Insecurity among HIV Positive Adult Patients Taking Highly Active AntiRetroviral Therapy at Arba Minch General Hospital, Southern Ethiopia, 2016. Gen Med (Los Angeles) 5: 300. doi: $10.4172 / 2327-5146.1000300$

Page 2 of 11

In poor localities, numerous HIV infected patients lack access to sufficient quantities of nutritious foods, which leads to non-compliance to treatment. Reduced food intake in HIV affected households could also be secondary to loss of income and food production capacity in the family due to labor loss, psychosocial factors, or medication sideeffects [4-6]. Like other chronic care drugs antiretroviral drugs are difficult to take on an empty stomach due to associated side effects, distance from health facility and transportation cost, search of work add additional burden on a patient with impaired immunity influences retention on HIV/AIDS treatment and care [7-9].

Food insecurity is obstacle to adherence to ART and upsurge transmission of HIV by increasing viral load and decreasing CD4 of patients, hence leads to increased HIV-related opportunistic infections and increased hospitalizations [10]. A lack of access to food drives families into social crisis, migration and displacement that subsequently puts them at increased risk of HIV infection and its consequences. In the community where there is High HIV prevalence societies may face cumulative reductions in food supply and increased labor costs and extending the effect of interactions beyond the individual to the household and societal levels [11-14].

Food insecurity not only increases the acquisition of HIV via vertical and horizontal transmission by compromised nutritional status but also barrier to adherence to care and treatment. Millions of HIV infected people live in countries with high levels of poverty and food insecurity. Food insecurity and HIV/AIDS are interlinked and causing significant morbidity and mortality in sub-Saharan Africa [15-17].

In Ethiopia about $10 \%$ of general population and $40.4 \%$ to $87.4 \%$ people living with HIV/AIDS will struggle to have access to "safe, sufficient and nutritious food" for themselves and for their families [18-20]. A similar study conducted in Humera Hospital in Northern Ethiopia among $376 \mathrm{HIV}$-infected adults, showed that $40.4 \%$ were food insecure.

Worldwide, over 842 million people were unable to meet their dietary energy requirements of which $98 \%$ have been reported in developing countries. More than 35 million people are living with HIV and most cases have been reported in low and middle-income countries, particularly in Sub Saharan Africa (SSA) [21]. Study conducted in Canadia among HIV-infected individuals receiving HAART showed that $71 \%$ were food insecure [22]. Study conducted in Democratic Republic of Congo, 57\% and in Namibia 92\% were food insecure respectively $[23,24]$. Study conducted in Kenya revealed that $20-50 \%$ of patients' were food insecure $[25,26]$. As research conducted in Kenya revealed that gender, employment, income, drinking water and sanitation were determinants of food insecurity [27].

A cross-sectional study conducted in South Africa revealed that the physiological complications of progression of HIV infection and poverty were determinants of insufficient consumption of a diet of adequate quality and quantity to booster immune function and support medical therapy [28]. Studies conducted in different parts of Africa showed that HIV/AIDS depletes financial capital, social capital and human capital as labor is lost through decreased productivity and the death of the productive member of the family [29,30]. A study conducted in Ethiopia showed that Household wealth assets are important to lessen financial burden of households during events of stress like HIV/AIDS [31].

As survey conducted in Kenya revealed that households affected by HIV/AIDS are particularly susceptible to food insecurity [32]. A study in rural Uganda showed HIV stigma was strongly associated with food insecurity [33]. Similar report showed that, within households affected by HIV, there is an increased risk of food insecurity secondary to reduced income as sick members are unable to work [34].

Low socio-economic status and desperation may drive people into high risk behavior for HIV like transactional sex, labor migration or engaging in transactional sex that increases the likelihood of infection while malnutrition increases the vulnerability to HIV infection among those who are exposed [35,36]. A research conducted in Uganda indicated that food insecurity is due to the fact that as poor households in urban areas struggle to meet urban expenses, they reduce the type, quantity and quality of food to compensate other absolute expense [37].

Study conducted in Africa revealed that malnutrition and with HIV/ AIDS weaken the immunity and, decreases CD4 count leads to appearance of Opportunities Infections (OIs), the appearance of OIs leads to increase viral replication and further damage to the immune system. HIV/AIDS-related morbidity and mortality is cause of hostile social and economic consequences like food insecurity for the households and society [38]. As cross-sectional study conducted in Zambia and Kenya and Uganda revealed that Food insecurity has been associated with decline in physical health, increased viral load, increased incidence of illness, and mortality [39,40].

HIV/AIDS deteriorates household food insecurity by targeting most productive and economic age group of the society and increasing burden on family caregivers. Food insecurity, leads to increased risk of HIV transmission and rapid disease progression [41]. The effect Food insecurity on adherence to HAART globally is multifactorial and different studies reported that lower levels of medication adherence among food insecure individuals taking HAART [42-44].

Ensuring food security and meeting the special nutritional needs to control disease progression and adhere to ART are vital for PLWHIVA to achieve the desired benefit from treatment provided [23,24]. Despite the fact that there is clear advantage on integrating HIV treatment and nutritional programs, data are deficient, on the optimum content and duration of nutritional support, and on ideal target recipients [45-47]. The status of food insecurity is not well known among adults HIV infected adult patients at Arba Minch General Hospital. Therefore to fill this gap this study was designed to determine the levels and predictors of food insecurity among adult patients taking highly active anti-retroviral therapy at Arba Minch General Hospital, southern Ethiopia.

\section{Methodology}

\section{Study area and period}

The study was conducted from February 15 to March 30, 2016 on HIV infected individuals in ART clinic of Arba Minch General Hospital, which is located about $500 \mathrm{~km}$ south from Addis Ababa, about $275 \mathrm{~km}$ from Hawassa, the capital of the SNNPR region. It is a public hospital which provides general health service and higher levels of clinical care for catchment area populations. It serves as training center for Medical and Health sciences student in collaborating with Arba Minch University. Additionally, the Hospital has been providing highly active antiretroviral therapy (HAART) for PLWHIVA Starting from 1996 for RVI Adults and pediatric Patients. 
Citation: Belijo ZN, Mensa M (2017) Levels and Predictors of Food Insecurity among HIV Positive Adult Patients Taking Highly Active AntiRetroviral Therapy at Arba Minch General Hospital, Southern Ethiopia, 2016. Gen Med (Los Angeles) 5: 300. doi: $10.4172 / 2327-5146.1000300$

Page 3 of 11

\section{Study design}

Hospital based cross-sectional study design was conducted.

\section{Source population}

The source population was all adult people who are enrolled in highly active anti-retro viral therapy and have full ART records at ART clinic of Arba Minch general Hospital.

\section{Study population}

The study population was selected adult people on antiretroviral therapy at ART clinic of Arba Minch general Hospital during the study period that fulfils the inclusion criteria.

\section{Inclusion and exclusion Criteria}

\section{Inclusion criteria}

The study includes all adult people on antiretroviral therapy with age of 18 years and more in Arba Minch General Hospital.

\section{Exclusion criteria}

Patients who were seriously ill and/or unable to communicate

Patients with incomplete clinical records

\section{Sample size determination}

Sample size determination was based on single population proportion formula. The prevalence of food insecurity among PLWHA patients was $63 \%$ from study conducted in Jimma University Specialized Hospital [19]. With 5\% marginal error and 95\% confidence interval (CI) and 10\% of non-response rate. Finally 394 were enrolled in the study.

$$
\mathrm{N}=\mathrm{Z} 2 . \mathrm{P} \cdot(1-\mathrm{P})
$$

d2

\section{Sampling technique}

Participated in the study were selected based on daily follow up of patient in chronic follow up clinic during the specified study periods. According to the hospital report, on average 20-30 patients that were currently having follow up in ART have been visiting the hospital daily and by taking average daily visit as 25 , approximately 750 patients were expected to visit the hospital in one month of study period. Since the sample size determined was 394 , to achieve the desired sample size sampling interval two was used. From the first two subjects, one patient was randomly selected by lottery method, and then every other patient was selected to participate in this study. Study participant exist interview was conducted in ART clinic in private room. Secondary data was collected from patient ART record by using data abstraction sheet [48].

\section{Variables of the study}

\section{Dependent variable}

Food insecurity

\section{Independent variable}

Socio demographic and economic factors: Age, Sex, Marital status, Residence, Educational status, Monthly income, source of food for household.

Behavioral factors: Smoking, khat chewing, alcohol consumption, use of drugs.

Disease condition and clinical related factors: Duration of illness, BMI, opportunistic infection, HIV stage, CD4 count, clinical AIDS staging, ART duration.

\section{Data collection procedure and instrument}

Amharic version of the survey questionnaire was used for data collection. The household food insecurity status of participant was assessed by using a short version of the Household Food Insecurity Access Scale (HFIAS) developed by the Food and Nutrition Technical Assistance (FANTA) project which was adapted to individual level. Each of the questions was asked with a re-call period of four weeks (30 days). The respondent was first asked an occurrence question that is, whether the condition in the question happened at all in the past four weeks (yes or no). If the respondent answers "yes" to an occurrence question, a frequency-of-occurrence question will be asked to determine whether the condition happened rarely (once or twice), sometimes (three to ten times) or often (more than ten times) in the past four week. It was computed and dichotomized into two categories; which is food insecure and food secure [49-52]. Weight of participants was taken by using standard beam balance and the scale was checked at zero before and after each measurement. Participants' weight was measured after removing heavy clothes and recorded to the nearest 0.1 $\mathrm{kg}$. Height measurement of participants was done using standard measuring scale after removing their shoes and recorded to the nearest $0.01 \mathrm{~cm}$.

\section{Data quality assurance}

Two diploma nurses as data collectors and one B.Sc. nurse as supervisor for maintaining data quality were recruited. Training was given for data collectors and supervisor for one day. Pre-test of the questionnaire was done on 20 clients in the nearby Health Center a week prior to the actual survey for 2 days to check for consistency and possible amendments were made based on findings from pre-test. Data collection process was strictly followed day to day by the supervisor and principal investigators.

\section{Data analysis}

The data collected from the respondents was entered in to Epi info 3.5.1 and exported to SPSS for windows-version 20 for analysis. Data analysis was conducted by cross tabulation to see the relationship between dependent and independent variable. Accordingly, simple frequencies, measure of central tendencies and measure of dispersions were calculated. Bivariate logistic regression analysis was computed to assess the crude association between explanatory variables and food insecurity. Finally Variables which showed association in binary logistic regression analysis and having P-value less than 0.25 were entered in to Multivariable logistic regression model, to identify independent predictors associated with outcome variable. Finally the level of significance was set at P-value less than 0.05. 
Citation: Belijo ZN, Mensa M (2017) Levels and Predictors of Food Insecurity among HIV Positive Adult Patients Taking Highly Active AntiRetroviral Therapy at Arba Minch General Hospital, Southern Ethiopia, 2016. Gen Med (Los Angeles) 5: 300. doi: $10.4172 / 2327-5146.1000300$

Page 4 of 11

\section{Operational definition}

Body Mass Index: was calculated as the weight (in kilograms) divided by the square of the height (in meters). BMI was stratified into the following groups according to established criteria: $<17 \mathrm{~kg} / \mathrm{m}^{2}$ (moderate to severe malnutrition), 17 to $18.5 \mathrm{~kg} / \mathrm{m}^{2}$ (mild malnutrition), 18.5 to $25 \mathrm{~kg} / \mathrm{m}^{2}$ (normal) and $>25 \mathrm{~kg} / \mathrm{m}^{2}$ (overweight and obese) [51].

Dietary diversity: is the number of reported different foods and food groups consumed in a household over a 24-hour period. This does not include food group consumed outside home. It is classified as low $<3$ food items, medium $4-6$ food items and $\geq 6$ food items as higher based on FANTA/FAO recommendations [52].

Food insecure: Individuals were labeled to be food insecure if they answer "Yes" to all the key questions designed to assess food insecurity and otherwise labeled as food secure.

Meal frequency: is the number of reported daily eating occasions by household members in a household experienced within a day. This does not include eating occasions by the household members experienced outside home. It classified as good when it is 3 and above with additional snack and poor when it is below 3 meals per day and good when $>3$ feed timers per day [52].

\section{Ethical clearance}

The study protocol was reviewed and approved by Arba Minch University ethical clearance committee. Permission letter was obtained from Gamo Gofa Zone health department and Arba Minch Hospital administration before data collection. Informed consent was obtained from respondents after explaining the purpose of study. Privacy and confidentiality also maintained throughout the data collection, analysis and manuscript preparation.

\section{Results}

\section{Socio demographic characteristics of the study participants}

There were 394 study participants involved in this study with response rate of $100 \%$. Majority of them $260(66 \%)$ were females followed by 134 (34\%) males. More than one third 127(39.3\%) of study participants were in age range of 30-39 years with Mean age of $26.65 \pm$ 10.48 years, ranging from $18-60$ years. More than one third $149(37.8 \%)$ of study participants completed secondary school and above followed by primary school $145(36.8 \%)$. With regard to occupational status about one half $185(46.9 \%)$ were government workers followed by $119(30.2 \%)$ farmers. Concerning the monthly income more than one third 154(39.0\%) of participants earn below 100 ETB per month (Table $1)$.

\begin{tabular}{|l|l|l|l|}
\hline \multicolumn{2}{|l|}{ Variable } & Frequency & Percent \\
\hline \multirow{2}{*}{ Sex } & Male & 134 & $34 \%$ \\
\cline { 2 - 4 } & Female & 260 & $66 \%$ \\
\hline \multirow{2}{*}{ Age } & $18-29$ & 73 & $18.50 \%$ \\
\cline { 2 - 4 } & $30-39$ & 171 & $43.40 \%$ \\
\cline { 2 - 4 } & $>40$ & 150 & $38.10 \%$ \\
\hline Residence & Urban & 305 & $77.40 \%$ \\
\hline
\end{tabular}

\begin{tabular}{|c|c|c|c|}
\hline & Rural & 89 & $22.50 \%$ \\
\hline \multirow[t]{8}{*}{ Ethnicity } & Gamo & 200 & $50.80 \%$ \\
\hline & Gofa & 28 & $7.10 \%$ \\
\hline & Wolayta & 31 & $7.90 \%$ \\
\hline & Amhara & 71 & $18.00 \%$ \\
\hline & Tigre & 17 & $4.30 \%$ \\
\hline & Gurage & 7 & $1.80 \%$ \\
\hline & Oromo & 24 & $6.10 \%$ \\
\hline & Others & 16 & $4.10 \%$ \\
\hline \multirow[t]{4}{*}{ Religion } & Orthodox & 254 & $64.50 \%$ \\
\hline & Muslim & 27 & $6.90 \%$ \\
\hline & Protestant & 105 & $26.60 \%$ \\
\hline & Catholic & 8 & $1.90 \%$ \\
\hline \multirow[t]{3}{*}{ Educational Status } & No Formal Education & 100 & $25.30 \%$ \\
\hline & Primary School & 145 & $36.80 \%$ \\
\hline & Secondary and Above & 149 & $37.80 \%$ \\
\hline \multirow[t]{3}{*}{ Occupational Status } & No Job & 90 & $22.80 \%$ \\
\hline & Government Workers & 185 & $46.90 \%$ \\
\hline & Farmer & 119 & $30.20 \%$ \\
\hline \multirow[t]{3}{*}{ Monthly Income in ETB } & Less than 1000 & 154 & $39.00 \%$ \\
\hline & $1000-2000$ & 115 & $29.10 \%$ \\
\hline & $>2000$ & 125 & $31.70 \%$ \\
\hline Others & \multicolumn{3}{|c|}{ Zayse, Oyda, hadiya, Kambata } \\
\hline
\end{tabular}

Table 1: Socio-demographic characteristics of adult patients taking HAART at Arba Minch General Hospital, Southern Region, Gamo Gofa Zone, March 2016.

\section{HIV/AIDS related clinical data}

Concerning HIV/AIDS related clinical data only 46(11.7\%) participants reported that they have experienced HAART related side effect in the past six months. About one fourth 91(23.1\%) of participants had experienced opportunistic infections in the past six months and acute diarrhea $31(34.1 \%)$ followed by pulmonary $\mathrm{TB}$ $22(24.2 \%)$ were commonly reported OIS. About one third 123(31.2\%) were on Cotrimoxazole preventive therapy, 22(5.6\%) of patients experienced pulmonary TB in the past six months and $18(81.8 \%)$ were currently taking anti-TB drugs and the remaining 4(18.2\%) completed TB therapy. About one fifth 68(17.3\%) of participants were on INH preventive therapy. Regarding WHO clinical staging secondary data from patient sheet revealed that majority $335(85 \%)$ having WHO stage I and II disease while 59(15\%) with stage III and IV disease. With regard to immunologic status majority 240(60.9\%) had CD4 count greater than 500 cells $/ \mathrm{mm}^{3}, 123(31.2 \%)$ had CD4 count between 250-500 and only $31(7.9 \%)$ had CD4 below 250 cells $/ \mathrm{mm}^{3}$. with regard to duration of the disease since diagnosis of HIV/AIDS majority of 
Citation: Belijo ZN, Mensa M (2017) Levels and Predictors of Food Insecurity among HIV Positive Adult Patients Taking Highly Active AntiRetroviral Therapy at Arba Minch General Hospital, Southern Ethiopia, 2016. Gen Med (Los Angeles) 5: 300. doi: $10.4172 / 2327-5146.1000300$

Page 5 of 11

respondents $289(73.4 \%)$ had HIV/AIDS for greater than 12 months. With regard to adherence to HAART majority $341(86.5 \%)$ had good

\begin{tabular}{|c|c|c|c|}
\hline \multicolumn{2}{|l|}{ Variables } & \multirow{2}{*}{$\begin{array}{l}\text { Frequency } \\
46\end{array}$} & \multirow{2}{*}{$\begin{array}{l}\text { Percentage (\%) } \\
11.7\end{array}$} \\
\hline Experience of any side effect on HAART in the past six month & Yes & & \\
\hline & No & 348 & 88.3 \\
\hline \multirow[t]{2}{*}{ Have you faced Opportunistic infections in the past six month } & Yes & 91 & 23.1 \\
\hline & No & 303 & 76.9 \\
\hline \multirow[t]{2}{*}{ Cotrimoxazole preventive therapy } & Yes & 123 & 31.2 \\
\hline & No & 271 & 68.8 \\
\hline \multirow[t]{2}{*}{ Isoniazid preventive therapy } & Yes & 68 & 17.3 \\
\hline & No & 326 & 82.7 \\
\hline \multirow[t]{2}{*}{ had pulmonary tuberculosis in the past six month } & Yes & 22 & 5.6 \\
\hline & No & 372 & 94.4 \\
\hline \multirow[t]{2}{*}{ Currently taking anti-TB drugs } & Yes & 18 & 81.8 \\
\hline & No & 4 & 18.2 \\
\hline \multirow[t]{2}{*}{ Experience of any side effect on anti-TB } & Yes & 6 & 30 \\
\hline & No & 14 & 70 \\
\hline \multirow[t]{2}{*}{ WHO clinical AIDS staging of a patients } & Stage I and II & 335 & 85 \\
\hline & Stage III and IV & 59 & 15 \\
\hline \multirow[t]{3}{*}{ The recent CD4 cell count in cell $/ \mathrm{mm}^{3}$} & Less than 250 & 31 & 7.9 \\
\hline & $250-500$ & 123 & 31.2 \\
\hline & Greater than 500 & 240 & 60.9 \\
\hline \multirow[t]{2}{*}{ Duration of HIVIAIDS since diagnosis } & $\leq 12$ month & 105 & 26.6 \\
\hline & $>12$ months & 289 & 73.4 \\
\hline \multirow[t]{2}{*}{ Adherence to HAART in past six month } & Good adherence & 341 & 86.5 \\
\hline & Poor adherence & 53 & 13.5 \\
\hline
\end{tabular}

Table 2: HIV/AIDS related clinical characteristics of adult patients taking HAART at Arba Minch General Hospital, Southern Region, Gamo Gofa Zone, March 2016.

\section{Behavioral factors}

Concerning behavioral factors majority 229(58.1\%), 279(70.8\%) and $317(80.5 \%)$ of participants reported that they do not smoke cigarette, do not drink alcohol and do not chew chat respectively. About one fifth $86(21.8 \%)$ of participants reported they were currently smoking cigarette, 26(6.6\%) reported that they currently drink alcohol and 25(6.3\%) were currently chewing chat (Table 3 ).

With regard to BMI of participants majority 250 (63.5\%) were normal $\left(18.5-25 \mathrm{~kg} / \mathrm{m}^{2}\right), 45(11.4 \%)$ were severely malnourished $<17$ $\mathrm{kg} / \mathrm{m}^{2}, 25(6.3 \%)$ moderately malnourished $\left(17.1-18.5 \mathrm{~kg} / \mathrm{m}^{2}\right)$ and the rest $74\left(18.8 \%\right.$ ) were overweight $25-30 \mathrm{~kg} / \mathrm{m}^{2}$ (Figure 2). adherence to treatment while 53(13.5\%) had poor adherence (Table 2 and Figure 1). 
Citation: Belijo ZN, Mensa M (2017) Levels and Predictors of Food Insecurity among HIV Positive Adult Patients Taking Highly Active AntiRetroviral Therapy at Arba Minch General Hospital, Southern Ethiopia, 2016. Gen Med (Los Angeles) 5: 300. doi: $10.4172 / 2327-5146.1000300$

Page 6 of 11

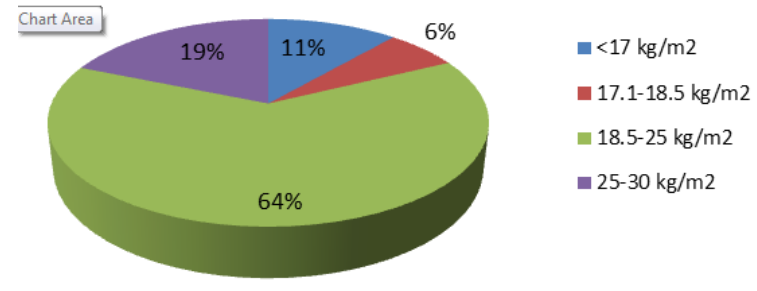

Figure 2: BMI of adult patients taking HAART at Arba Minch General Hospital, Southern Region, Gamo Gofa Zone, March 2016.

\section{Nutritional status, dietary diversity}

Concerning Daily eating pattern 92(23.4\%) consumed less than three meals per day. The dietary diversity score analysis indicates that $26(6.6 \%)$ of the respondents consumed low dietary diversity which less than 3 food items per day. The rest $109(27.7 \%)$ and $259(65.7 \%)$ of respondents consume medium (4-5 food groups) and high (6-12 food groups) respectively. Majority of respondent 354(89.8\%) get their food by purchasing followed by $24(6.1 \%)$ from house hold farm and $16(4.1 \%)$ from relatives or organization support. Concerning meal frequency one fourth of them had below 3 meals per day (Table 4).

\begin{tabular}{|l|l|l|l|}
\hline Behavioral related factors & Frequency & Percent \\
\hline Have you ever smoked cigarette? & Yes & 86 & 21.8 \\
\cline { 2 - 4 } & No & 229 & 58.1 \\
\cline { 2 - 4 } & Ex-smoker & 79 & 20.1 \\
\hline Have you ever drunk alcohol? & Yes & 26 & 6.6 \\
\cline { 2 - 4 } & No & 279 & 70.8 \\
\cline { 2 - 4 } Have you ever used chat & Ex-drunker & 89 & 22.6 \\
\cline { 2 - 4 } & Yes & 25 & 6.3 \\
\cline { 2 - 4 } & No & 317 & 52 \\
\hline
\end{tabular}

Table 3: Behavioral factors of adult patients taking HAART at Arba Minch General Hospital, Southern Region, Gamo Gofa Zone, March 2016.

\begin{tabular}{|c|c|c|c|}
\hline \multicolumn{2}{|l|}{ Variables } & \multirow{2}{*}{$\begin{array}{l}\text { Frequency } \\
250\end{array}$} & \multirow{2}{*}{$\begin{array}{l}\text { Percent } \\
63.5\end{array}$} \\
\hline Daily eating pattern of last 6 month & Three meals and above & & \\
\hline & Two meals and eating between meals & 52 & 13.2 \\
\hline & Below three meals & 92 & 23.4 \\
\hline \multirow[t]{3}{*}{ Dietary diversity in the last $24 \mathrm{hrs}$} & Less than three food items & 26 & $6.60 \%$ \\
\hline & $4-5$ food items & 109 & 27.7 \\
\hline & 6 and above food items & 259 & $65.70 \%$ \\
\hline \multirow[t]{3}{*}{ Main source of food for your household the last six month } & Purchase(Market/grocery store) & 354 & 89.8 \\
\hline & Household farm/garden & 24 & 6.1 \\
\hline & Relatives and friends & 16 & 4.1 \\
\hline
\end{tabular}

Table 4: Nutritional status and dietary diversity of adult patients taking HAART at Arba Minch General Hospital, Southern Region, Gamo Gofa Zone, March 2016.

Concerning type of food households consumed in $24 \mathrm{hrs}$ almost all households had consumed cereal based foods followed by oil and fat, vegetables, and legumes. The consumption of animal source (fish, meat, milk and egg) foods groups was low (Figure 3). 
Citation: Belijo ZN, Mensa M (2017) Levels and Predictors of Food Insecurity among HIV Positive Adult Patients Taking Highly Active AntiRetroviral Therapy at Arba Minch General Hospital, Southern Ethiopia, 2016. Gen Med (Los Angeles) 5: 300. doi: $10.4172 / 2327-5146.1000300$

Page 7 of 11

\section{Prevalence of food insecurity and copying strategy}

Respondents were asked 20 series of questions, 10 main and 10 minor questions adapted from household Food Insecurity Access Scale (HFIAS) developed by the Food and Nutrition Technical Assistance (FANTA). One hundred thirty five (34.3\%) reported that they worried about finding enough food for household, 247(62.7\%) were Not able to eat the kinds of foods they preferred, 276(70.1\%) consume a limited variety of foods due to a lack of resources, $317(80.5 \%)$ consume some foods that they really did not want to eat, $80(20.3 \%)$ consume less meal than they felt they needed, 302(76.6\%) consume fewer than three meals in a day. Seventy eight (19.8\%) of Households didn't have food on hand, 102(25.9\%) went to sleep at night hungry and 77(19.5\%) lived a whole day without eating anything. The Prevalence of food insecurity was $77(19.5 \%)$ while $317(80.5 \%)$ were food secure (Table 5).

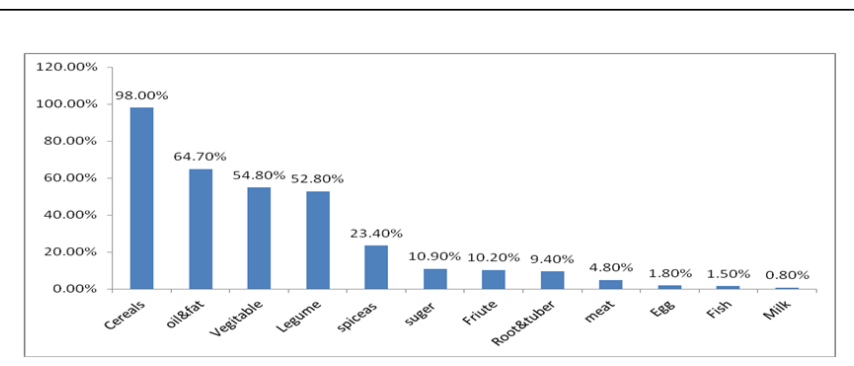

Figure 3: Food groups consumed by respondents within 24 hours, of HIV positive Adults attending ART in Southern Ethiopia, Gamo Gofa Zone, Arba Minch General Hospital, 2016 ( $\mathrm{n}=394)$.

\begin{tabular}{|c|c|c|c|c|}
\hline S.No. & \multicolumn{2}{|l|}{ Factors related to food security status } & Frequency & Percent \\
\hline \multirow{2}{*}{1} & \multirow[t]{2}{*}{ Households worry about finding enough food } & Yes & 135 & 34.3 \\
\hline & & No & 259 & 65.7 \\
\hline \multirow[t]{3}{*}{2} & \multirow[t]{3}{*}{ How often } & Rarely & 96 & 71.1 \\
\hline & & Sometimes & 28 & 20.7 \\
\hline & & Often & 11 & 8.1 \\
\hline \multirow[t]{2}{*}{3} & \multirow[t]{2}{*}{ Not able to eat the kinds of foods you preferred } & Yes & 247 & 62.7 \\
\hline & & No & 147 & 37.3 \\
\hline \multirow[t]{3}{*}{4} & \multirow[t]{3}{*}{ How often } & Rarely & 17 & 6.9 \\
\hline & & Sometimes & 162 & 65.6 \\
\hline & & Often & 68 & 27.5 \\
\hline \multirow[t]{2}{*}{5} & \multirow[t]{2}{*}{ Eat a limited variety of foods due to a lack of resources } & Yes & 276 & 70.1 \\
\hline & & No & 118 & 29.9 \\
\hline \multirow[t]{2}{*}{6} & \multirow[t]{2}{*}{ How often } & Rarely & 26 & 9.4 \\
\hline & & Sometimes & 250 & 90.6 \\
\hline \multirow[t]{2}{*}{7} & \multirow[t]{2}{*}{ Eat some foods that you really did not want to eat } & Yes & 317 & 80.5 \\
\hline & & No & 77 & 19.5 \\
\hline \multirow[t]{2}{*}{8} & \multirow[t]{2}{*}{ How often } & Rarely & 168 & 53 \\
\hline & & Sometimes & 149 & 47 \\
\hline \multirow[t]{2}{*}{9} & \multirow[t]{2}{*}{ Eat less meal than you felt you needed } & Yes & 80 & 20.3 \\
\hline & & No & 314 & 79.7 \\
\hline \multirow[t]{3}{*}{10} & \multirow[t]{3}{*}{ How often } & Rarely & 23 & 28.8 \\
\hline & & Sometimes & 35 & 43.8 \\
\hline & & Often & 22 & 27.5 \\
\hline \multirow[t]{2}{*}{11} & \multirow[t]{2}{*}{ Eat fewer than three meals in a day } & Yes & 302 & 76.6 \\
\hline & & No & 92 & 23.4 \\
\hline 12 & How often & Rarely & 210 & 69.5 \\
\hline
\end{tabular}


Citation: Belijo ZN, Mensa M (2017) Levels and Predictors of Food Insecurity among HIV Positive Adult Patients Taking Highly Active AntiRetroviral Therapy at Arba Minch General Hospital, Southern Ethiopia, 2016. Gen Med (Los Angeles) 5: 300. doi: $10.4172 / 2327-5146.1000300$

Page 8 of 11

\begin{tabular}{|c|c|c|c|c|}
\hline & & Sometimes & 32 & 10.6 \\
\hline & & Often & 60 & 19.9 \\
\hline \multirow[t]{2}{*}{13} & \multirow[t]{2}{*}{ Household do not have food on hand } & Yes & 78 & 19.8 \\
\hline & & No & 316 & 80.2 \\
\hline \multirow[t]{2}{*}{14} & \multirow[t]{2}{*}{ How often } & Sometimes & 52 & 66.7 \\
\hline & & Often & 26 & 33.3 \\
\hline \multirow[t]{2}{*}{15} & \multirow[t]{2}{*}{ Households faced no way of getting more food } & Yes & 85 & 21.6 \\
\hline & & No & 309 & 78.4 \\
\hline \multirow[t]{2}{*}{16} & \multirow[t]{2}{*}{ How often } & Rarely & 18 & 21.2 \\
\hline & & Sometimes & 67 & 78.8 \\
\hline \multirow[t]{2}{*}{17} & \multirow[t]{2}{*}{ Go to sleep at night hungry } & Yes & 102 & 25.9 \\
\hline & & No & 292 & 74.1 \\
\hline \multirow[t]{2}{*}{18} & \multirow[t]{2}{*}{ How often } & Rarely & 8 & 7.8 \\
\hline & & Sometimes & 94 & 92.2 \\
\hline \multirow[t]{2}{*}{19} & \multirow[t]{2}{*}{ Household member go a whole day without eating anything } & Yes & 77 & 19.5 \\
\hline & & No & 317 & 80.5 \\
\hline \multirow[t]{2}{*}{20} & \multirow[t]{2}{*}{ How often } & Rarely & 58 & 75.3 \\
\hline & & Sometimes & 19 & 24.7 \\
\hline
\end{tabular}

Table 5: Food security status in the past four weeks of adult patients taking HAART at Arba Minch General Hospital, Southern Region, Gamo Gofa Zone, March 2016.

\section{Factors associated with food insecurity}

In this study, both binary and multivariate logistic regression analysis were computed. Binary logistic regression analysis was computed to show factors associated with food insecurity. Being female $[\mathrm{COR}=4.31(2.13,8.68)]$; Rural Residence $[\mathrm{COR}=4.71(2.76$, 8.06)]; Monthly income less than 1000 Eth birr [COR=6.54(3.07, 13.94)] and those between 1000- 2000 Eth birr $[\mathrm{COR}=4.78$ $(2.47,9.28)]$; being WHO clinical stage three and four [COR=6.95(3.82,12.65)]; Developing OIS [COR=7.08(4.11, 12.22)] and poor treatment adherence $[\mathrm{COR}=10.02(5.32,18.89)]$ were significantly associated with food insecurity. Multivariable logistic regression was computed to identify independent predictors of food insecurity after excluding confounding factors and Being female $[\mathrm{AOR}=2.93(1.16,7.40)]$; Rural residence $[\mathrm{AOR}=3.59(1.65,7.836)]$ : monthly income less than 1000 Eth birr $[\mathrm{AOR}=6.16(2.33,16.32)]$ and those between 1000- 2000 Eth birr $[\mathrm{AOR}=5.72(2.47,13.38)]$; Having WHO clinical three and four disease $[\mathrm{AOR}=4.78(1.95,11.69)]$; Developing OIS $[\mathrm{AOR}=8.03(3.84,16.78)]$ and Poor adherence to treatment $[\mathrm{AOR}=8.96(3.48,23.05)]$ were independent predictors of food insecurity (Table 6).

\begin{tabular}{|c|c|c|c|c|c|c|c|}
\hline \multirow[t]{9}{*}{ Food insecure(a) } & \multirow{2}{*}{\multicolumn{2}{|c|}{ Variables }} & \multicolumn{2}{|c|}{ Food insecurity } & \multirow{3}{*}{$\begin{array}{l}\text { COR with } 95 \% \mathrm{CL} \\
1\end{array}$} & \multirow{3}{*}{$\begin{array}{l}\text { AOR with } 95 \% \mathrm{CI} \\
1\end{array}$} & \multirow{3}{*}{$\begin{array}{l}\text { P-value } \\
1\end{array}$} \\
\hline & & & Yes $(n=77)$ & No $(n=317)$ & & & \\
\hline & \multirow[t]{2}{*}{ Sex } & Male & $10(13.0 \%)$ & $124(39.1 \%)$ & & & \\
\hline & & Female & $67(87.0 \%)$ & $193(60.9 \%)$ & $4.31(2.13,8.68)$ & *2.93(1.16,7.40) & 0.023 \\
\hline & \multirow[t]{2}{*}{ Residence } & Urban & $40(51.9 \%)$ & $265(83.6 \%)$ & 1 & 1 & 1 \\
\hline & & Rural & $37(48.1 \%)$ & $52(16.4 \%)$ & $4.71(2.76-8.06)$ & ${ }^{*} 3.59(1.65,7.836)$ & 0.001 \\
\hline & \multirow[t]{3}{*}{ Monthly Income in Birr } & $<1000$ & $55(71.4 \%)$ & $99(31.2 \%)$ & $6.54(3.07,13.94)$ & ${ }^{*} 6.16(2.33,16.32)$ & 0.0001 \\
\hline & & $1000-2000$ & $9(11.7 \%)$ & $106(33.4 \%)$ & $4.78(2.47,9.28)$ & ${ }^{*} 5.72(2.47,13.38)$ & 0.0001 \\
\hline & & $>2000$ & $13(16.9 \%)$ & $112(35.3 \%)$ & 1 & 1 & 1 \\
\hline
\end{tabular}


Citation: Belijo ZN, Mensa M (2017) Levels and Predictors of Food Insecurity among HIV Positive Adult Patients Taking Highly Active AntiRetroviral Therapy at Arba Minch General Hospital, Southern Ethiopia, 2016. Gen Med (Los Angeles) 5: 300. doi: $10.4172 / 2327-5146.1000300$

Page 9 of 11

\begin{tabular}{|c|c|c|c|c|c|c|c|}
\hline & \multirow[t]{2}{*}{ WHO Stage of disease } & Stage I \& II & $46(59.7 \%)$ & $289(91.2 \%)$ & 1 & 1 & 1 \\
\hline & & Stage III \& IV & $31(40.3 \%)$ & $28(8.8 \%)$ & $6.95(3.82,12.65$ & *4.78(1.95,11.69) & 0.001 \\
\hline & \multirow[t]{2}{*}{ Developing OIS } & Yes & $43(55.8 \%)$ & $48(15.1 \%)$ & $7.08(4.11,12.22)$ & *8.03(3.84,16.78) & 0.001 \\
\hline & & No & $34(44.2 \%)$ & $269(84.9 \%)$ & 1 & 1 & 1 \\
\hline & \multirow[t]{2}{*}{ Adherence to treatment } & Good adherence & $45(58.4 \%)$ & $296(93.4 \%)$ & 1 & 1 & 1 \\
\hline & & Poor adherence & $32(41.6 \%)$ & $21(6.6 \%)$ & $10.02(5.32,8.89)$ & *8.96(3.48,23.05) & 0.001 \\
\hline $\begin{array}{l}\text { Reference category } \\
\text { "significant factors }\end{array}$ & food secure ${ }^{a}$ & & & & & & \\
\hline
\end{tabular}

Table 6: Binary and Multivariable logistic regression of Variables predicting the likelihood food insecurity among adult patients taking HAART at Arba Minch General Hospital, Southern Region, Gamo Gofa Zone, March 2016.

\section{Discussion}

This study revealed the level and factors associated with food insecurity among adult patients taking highly active anti-retroviral therapy and the prevalence of food insecurity was $77(19.5 \%)$. This finding relatively similar to study done in Kenya prevalence of food insecurity ranged from $20-50 \%$ [25] but lower than study conducted in different part of Africa like Uganda [37.9\%], Democratic Republic of the Congo [57\%], Windhoek, Namibia [67\%] [28-30] as well as in different parts of Ethiopian Public Health Hospital such as in Humera Hospital in Northern Ethiopia, the prevalence of food insecurity among 376 HIV-infected adults was [40.4\%], Butajira Hospital, Jimma University Referral Hospital and Fitche Zonal Hospital in Oromia region the prevalence of food insecurity was $67.5 \%, 83 \%$ and $87.4 \%$ respectively [18-20,31]. The variation among different parts of the countries could be due to the existence of different socio-economic status, the health intervention measurement taken, difference in study years and study setting. In addition the low prevalence of food insecurity due to variation in tools used to measure food insecurity.

These study showed that females were 2.9 times $[\mathrm{AOR}=2.93(1.16$, 7.40)] more likely food insecure than males. This finding is in line with study conducted in South Africa [33]. This is due to the fact that women who had increased food insecurity due to limited resources and low paid job opportunity in this set up. Participant who have low income less than 1000 Ethiopian birr and from 1001-2000 ETB per month were 6 times $[\mathrm{AOR}=6.16(2.33,16.32)]$ and 5 times $[\mathrm{AOR}=5.72$ $(2.47,13.38)]$ respectively more likely exposed for food insecurity as compared those who earn more than 2000 ETB per month. This finding is in line with research conducted in Chulaimbo Sub-District Hospital in Kenya [32], Butajira, Jimma University referral Hospital and Fiche which reveals that socio demographic factors such as gender, employment and income were closely related determinants of food insecurity [18-20]. This due to the fact that HIV infection associated impaired productivity and become unemployed due to frequent illness, finally end up food insecure. In addition to this HIV/AIDS is affecting all spheres of human activity and performance. It depletes financial capital (savings and investments), social capital, as it affects demography of the family and human capital as labor is lost through the death of the productive member of the family [34]. In addition to this when income diminishes in household may cause inadequate quality and quantity of food intake due to unable to purchase variety and preferences of the type of food. Moreover, it will cause the individuals to reduce dietary energy intake below daily requirements.
Rural residents were 3.6 times $[\mathrm{AOR}=3.59(1.65,7.836)]$ more likely to be food insecure than those living in urban area. This finding is Consistence with a study conducted at Butajira Hospital, Southern Ethiopia [18]. This association might be due to lower socio-economic status, lower food access and diversity, higher infectious disease and lack of infrastructure services in rural residence than in urban residence.

This study revealed that participants who are on WHO stage III and IV were 4.7 times $[\mathrm{AOR}=4.78(1.95,11.69)]$ more likely to develop food insecurity as compared to WHO stage I and II. This finding is supported by research conducted in Zambia and Kenya, As WHO staging increase the patient become physically week and CD4 count decreased it result to be less productive. As indicated in different studies food insecurity has been associated with a range of adverse clinical effects among PLWHA, including declines in physical health status, decreased viral suppression increased incidence of serious illness and end up in food insecurity [47]. Furthermore HIV/AIDS worsens family food insecurity because of the debilitation of the most productive household members, decreased individual and household economic capacity, and increased cost of expense on medical for medical activity which expose families for food insecure.

In this study patients Non-adherent treatment were 8.9 times $[\mathrm{AOR}=8.96(3.48,23.05)]$ more likely exposed to food insecurity as compared to patients adhered to treatment. This is strongly supported by Studies from British Columbia and San Francisco [49], have found lower levels of medication adherence among food insecure individuals on ART. Study conducted in rural Uganda showing that food insecurity is associated with non-adherence to ART [46]. Food insecurity has emerged as a key structural barrier that affects adherence to ART in both resource-rich and constrained settings. This could be explained by non-adherence related treatment failure and immunologic weakness that could reduce patient performance and associated CD4 cell reduction which could give opportunity for development of opportunistic infections that could further limit patients' ability to work and reduce productivity.

This study also revealed that patients who developed opportunistic infection were 8 times $[\mathrm{AOR}=8.03(3.84,16.78)]$ more likely exposed to food insecurity as compared to their counter parts. This is consistent with study conducted in Fitche Zonal Hospital in Oromia region [20]. This could be due to the frequent illness caused significant disability leading to reduced productivity depletion of savings and inability to earn more incomes. 
Citation: Belijo ZN, Mensa M (2017) Levels and Predictors of Food Insecurity among HIV Positive Adult Patients Taking Highly Active AntiRetroviral Therapy at Arba Minch General Hospital, Southern Ethiopia, 2016. Gen Med (Los Angeles) 5: 300. doi: $10.4172 / 2327-5146.1000300$

Page 10 of 11

\section{Conclusion}

In conclusion about one fifth of participants were food insecure. The prevalence of food insecurity is relatively lower than similar studies in different settings in Ethiopia. About one tenth of participants reported that they had experienced HAART related side effect in the past six months. One quarter of participants consumed less than three meals per day. Almost all individual have consumed cereal based foods followed by oil and fat but animal source food feeding practice was poor. Majority of respondents depended on help from a friend or relatives as copying strategy. Factors like being female, low monthly income, rural residence, having WHO stage III and IV disease, developing opportunistic infection and non-adherence to ART treatment were independent predictors of food insecurity.

\section{Limitation of the Study}

The findings of this study should be interpreted in light of its limitations. This study used patient interview about events in the past six month there could be associated recall bias; there is possibility of desirability bias by patients as they might report what seems right not the actual practice. It cannot show causality of food security in this population.

\section{Recommendations}

Based on findings from this study the following recommendations were made to the following three responsible bodies:

\section{To people living with HIV/AIDS}

Designing strategies to improve adherence to treatment, to control prevent disease progression and to improve immune status and patient wellbeing so that they can be productive to further reduce the reported food insecurity.

\section{To Arba Minch General hospital}

It is important to Screen patients for OIs, awareness creation about HIV/AIDS and adherence counselling to medical treatment to improve health status to improve economic productivity.

\section{To Government and stakeholders}

Females, rural residents and earing low monthly income were highly vulnerable to food insecurity. Therefore it is important to empower these segments of population to alleviate food insecurity problem.

\section{Acknowledgment}

We would like to give special thanks to Arba Minch University College of Medicine and Health Science for giving us chance to conduct this study. Our acknowledgment extends to our Advisors Dr. Amsalu Alagaw and Mrs. Meseret Girma for their support and comments on the proposal and the research paper. We would also like to thank participants of this study and Arba Minch General Hospital for the willingness to participate in the study and the cooperation to give important information conserving this study respectively. Last, but not the least, we would like to give thanks to our devoted family and friends who provide us unreserved support during the whole journey of this work.

\section{Competing Interests}

There is no financial or personal relationship(s) which may have inappropriately influenced us during writing this article.

\section{Authors' Contributions}

Zelalem Nigatu and Mende Mensa conceived the study, analyzed the data and prepared the draft for publication and polished the language and we Approved the final manuscript.

\section{References}

1. Haile HK, Alemu ZG, Kudhlande G (2006) Causes of household food insecurity in koredegaga peasant association, oromiya zone, ethiopia.

2. The US President's Emergency Plan for AIDS Relief (2006) Report on Food and Nutrition for People Living with HIV/AIDS, USA.

3. (WHO)World Health Organization (2003) Nutrition requirements for people living with HIV/AIDS: Report of a technical consultation, Geneva.

4. Castleman T, Seumo-Fosso E, Cogill B (2003) Food and nutrition implications of antiretroviral therapy in resource limited settings.

5. Piwoz EG, Preble EA (2000) HIV/AIDS and nutrition: A review of the literature and recommendations for nutritional care and support in subSaharan Africa. U.S. Agency for International Development, Discussion paper, Washington D.C, USA.

6. Bukusuba J, Kikafunda JK, White head RG (2007) Food security status in households of people living with HIV/AIDS (PLWHA) in a Ugandan urban setting. Br J Nutr $98: 211-217$.

7. Mukherjee JS, Ivers LC, Leandre F, Farmer P, Behforouz H (2006) Antiretroviral therapy in resource-poor settings. Decreasing barriers to access and promoting adherence. J Acquir Immune Defic Syndr 43: S123S126.

8. Mahlungulu S, Grobler LA, Visser ME, volmink J (2007)Nutritional interventions for reducing morbidity and mortality in people with HIV. Cochrane database Syst Rev CD004536.

9. Nachega JB, Knowlton AR, Deluca A, Schoeman JH, Watkinson L, et al. (2006) Treatment Supporter to Improve Adherence to Antiretroviral Therapy in HIV-Infected South African Adults: A Qualitative Study. JAcquir Immune Defic Syndr 43: S127-S133.

10. Weiser SD, Tsai AC, Gupta R, Frongillo EA, Kawuma A, et al. (2012) Food insecurity is associated with morbidity and patterns of healthcare utilization among HIV-infected individuals in a resource-poor setting. AIDS 26: 67-75.

11. Loevinsohn M, Gillespie S (2003) HIV/AIDS, food security and rural livelihoods: understanding and responding. International Food Policy Research Institute (IFPRI), Discussion paper, Washington D.C, USA.

12. Rollins N (2007) Food Insecurity-A Risk Factor for HIV Infection. PLoS Med 4: 1576-1577.

13. Jayne T, Villarreal M, Pingali P, Hemrich G (2004) Interactions between the Agricultural Sector and the HIV/AIDS Pandemic: Implications for Agricultural Policy. Department of Agricultural Economics, East Lansing, MI.

14. Gillespie S, Gillespie SR (2006) AIDS, poverty, and hunger: Challenges and responses. International Food Policy Research Institute (IFPRI), Washington D.C, USA.

15. Aberman NL, Rawat R, Drimie S, Claros JM, Kadiyala S (2014) Food Security and Nutrition Intervention in Response to the AIDS Epidemic: Assessing Global Action and Evidence. AIDS Behav 18: S554-S565.

16. Webb-Girard A, Cherobon A, Mbugua S, Kamau-Mbuthia E, Amin A, et al. (2012) Food insecurity is associated with attitudes towards exclusive breastfeeding among women in urban Kenya. Matern Child Nutr 8: 199214.

17. Sera Y, Amanda W, Sandi M, Sheri DW (2014) A review of the role of food insecurity in adherence to care and treatment among adult and 
Citation: Belijo ZN, Mensa M (2017) Levels and Predictors of Food Insecurity among HIV Positive Adult Patients Taking Highly Active AntiRetroviral Therapy at Arba Minch General Hospital, Southern Ethiopia, 2016. Gen Med (Los Angeles) 5: 300. doi: $10.4172 / 2327-5146.1000300$

Page 11 of 11

pediatric populations living with HIV and AIDS. AIDS Behav 18: S505 S515.

18. Gedle D, Mekuria G, Kumera G (2015) Food Insecurity and its associated factors among people living with HIV/ AIDS receiving anti-retroviral therapy at Butajira Hospital, Southern Ethiopia. J Nutr Food Sci 5: 347.

19. Tiyou A, Belachew T, Alemseged F, Biadgilign S. (2012) Food insecurity and associated factors among HIV-infected individuals receiving highly active antiretroviral therapy in Jimma zone Southwest Ethiopia. Nutr J 11: 51.

20. Belachew T, Bayissa DD, Temamen T, Belachew T (2015) Food Insecurity and Associated Factors among People Living with HIV Attending ART Clinic in Fitche Zonal Hospital, Ethiopia. J Pharm and Alt Med.

21. David AW, Cynthia LG, Cynthia AL, Norma M, Richard AE, et al. (1998) Weight loss as a predictor of survival and disease progression in HIV infection. J Acquir Immune Defic Syndr Hum Retrovirol 18: 80-85.

22. Sanjobo N, Frich JC, Fretheim A (2008) Barriers and facilitators to patients' adherence to antiretroviral treatment in Zambia: A qualitative study. J Social Aspects HIV/AIDS 5: 136-143.

23. Blumberg SJ, Dickey WC (2003) Prevalence of HIV risk behaviors, risk perceptions, and testing among US adults with mental disorders. J Acquir Immune Defic Syndr 32: 77-79.

24. Katona P, Katona AJ. (2008) The interaction between nutrition and infection. Clin Infect Dis 46: 1582-1588.

25. Piwoz E (2004) Nutrition and HIV / AIDS: Evidence, gaps, and priority actions. Academy for Educational Development, Washington DC.

26. Shelley M (2013) WHO, World Food Programme, and International Fund for Agricultural Development. 2012. The State of Food Insecurity in the World 2012. Economic growth is necessary but not sufficient to accelerate reduction of hunger and malnutrition. Rome, FAO. Adv Nutr 4: 126-127.

27. Anema A, Druyts E, Weiser SD, Fernandes KA, Brandson EK, et al. (2014) Prevalence and correlates of food insecurity in a Canadian cohort of HIV-infected individuals receiving highly active antiretroviral therapy.

28. Musumari PM, Wouters E, Kayembe PK, Kiumbu NM, Mbikayi SM, et al. (2014) Food insecurity is associated with increased risk of non-adherence to antiretroviral therapy among HIV-infected adults in the Democratic Republic of Congo: A cross-sectional study. PloS one 9: e85327.

29. Hong SY, Fanelli TJ, Jonas A, Gweshe J, Tjituka F, et al. (2014) Household food insecurity associated with antiretroviral therapy adherence among HIV-infected patients in Windhoek, Namibia. J Acquir Immune Defic Syndr 67: e115-e122.

30. Mamlin J, Kimaiyo S, Lewis S, Tadayo H, Jerop FK, et al. (2009) Integrating nutrition support for food-insecure patients and their dependents into an HIV care and treatment program in Western Kenya. Am J Public Health 99: 215-221.

31. Hadgu TH, Worku W, Tetemke D, Berhe H (2013) Undernutrition among HIV positive women in Humera hospital, Tigray, Ethiopia, 2013: Antiretroviral therapy alone is not enough, cross sectional study. BMC public health 13: 943.

32. Agatha CO, Mary KW, Grace M, Rose K (2011) Body Composition and CD4 Cell Count of HIV Sero-Positive Adults Attending Out-Patient Clinic in Chulaimbo Sub-District Hospital Kenya. Pak J Nutr 10: 582588.

33. Oldewage TW, Dicks E, Napier C (2006) Poverty, household food insecurity and nutrition: Coping strategies in an informal settlement in the Vaal Triangle, South Africa. Public Health 120: 795-804.

34. Hlanze Z, Gama T, Mondlane S. (2005) The Impact of HIV/AIDS and Drought on Local Knowledge Systems for Agrobiodiversity and Food Security. Rome: FAO.
35. Wiesmann S (2006) A Basis for Cross-country Comparisons. Global Hunger Index, International Food Policy Research Institute, Washington DC.

36. Laura CA, Ayalew T, Fasil T, Sandro G, Craig H (2011) Food insecurity, childhood illness and maternal emotional distress in Ethiopia. Public Health Nutr 15: 648- 655.

37. Fafchamps M. (1992) Solidarity networks in preindustrial societies: rational peasants with a moral economy. Econ Dev Cult Change 41: 147174.

38. Tsai AC, Bangsberg DR, Emenyonu N, Senkungu JK, Martin JN, et al. (2011) The social context of food insecurity among people living with HIV/AIDS in rural Uganda. Soc Sci Med 73: 1717-1724.

39. Crush J, Frayne B, Grant M (2006) The Regional Network on HIV/AIDS, Livelihoods and Food Security/International Food Policy Research Institute/Southern African Migration Project. IFPRI, Washington.

40. Piwoz EG, ME Bentley (2005) Women's Voices, Women's Choices: The Challenge of Nutrition and HIV/AIDS. J Nutr 135: 933-937.

41. FAO Nutritional care and support for PLHIV training course or use in Ethiopia. http://fitun.etharc.org/arvinfo/nutrition_eth_partic.pdf jan 2016.

42. Nutrition Policy Paper 20 (2001) Nutrition and HIV/AIDS United Nations Administrative Committee on Coordination, Sub Committee on Nutrition. Report of the 28th Session Symposium Held in April 3-4, 2001.

43. Crush J, Frayne B, Grant M (2006) The Regional Network on HIV/AIDS, Livelihoods and Food Security. International Food Policy Research Institute, Southern African Migration Project Washington.

44. Bukusuba J, Kikafunda JK, Whitehead RG (2007) Food security status in households of people living with HIV/AIDS (PLWHA) in a Ugandan urban setting. Br J Nutr 98: 211-217.

45. Baiyegunhi LJS, Makwangudze KE (2013) Home gardening and food security status of HIV/AIDS Affected Households in Mpophomeni, KwaZulu-Natal Province, South Africa. J Hum Ecol 44: 1-8.

46. Stang AL, Wamai N, Mermin J, Awor AC, Bunnell RE (2007) Trends and predictors of quality of life among HIV- infected adults taking highly active antiretroviral therapy in rural Uganda. AIDS Care 19: 626-636.

47. Samuels FA, Rutenberg N (2011) "Health regains but livelihoods lag": Findings from a study with people on ART in Zambia and Kenya. AIDS Care 23: 748-754.

48. Kalichman S, Cherry C, Amaral C, White D, Kalichman M, et al. (2010) Health and treatment implications of food insufficiency among people living with HIV/AIDS, Atlanta, Georgia. J Urban Health 87: 631-641.

49. Weiser SD, Fernandes KA, Anema A, Brandson EK, Lima VD, et al. Food insecurity as a barrier to antiretroviral adherence among HIV-infected individuals in British Columbia. IAS conference on HIV pathogenesis, treatment and prevention, Cape Town, South Africa.

50. Lisa AE, Demetria NC, Eileen VP, Kate BC, Michael PC, et al. (2014) Exploring the relationships among food insecurity, alcohol use, and sexual risk taking among men and women living in South African townships. J Prim Prev 35: 225-265.

51. Molla D, Fekadu M, Dereje B (2013) Nutritional Status and Associated Factors Among Adult HIV/AIDS Clients in Felege Hiwot Referral Hospital, Bahir Dar, Ethiopia. Science J Public Health 1: 24-31.

52. FAO (2006) Baseline Survey Report Protecting and Improving Household Food Security and Nutrition in HIV/AIDS Affected Areas in Manica and Sofala Province, Maputo, Mozambique. 